\title{
Impact of the Degree of Technical Capability Structure Matching on the Intellectual Property Risk in Industry-University-Institute Cooperation
}

\author{
Yong Dai, Zhenyang Lin \\ School of Business Administration, South China University of Technology, Guangzhou, China \\ Email: allin_lzy@hotmail.com
}

How to cite this paper: Dai, Y. and Lin, Z.Y. (2017) Impact of the Degree of Technical Capability Structure Matching on the Intellectual Property Risk in Industry-University-Institute Cooperation. Open Journal of Business and Management, 5, 312334.

https://doi.org/10.4236/ojbm.2017.52028

Received: April 3, 2017

Accepted: April 25, 2017

Published: April 30, 2017

Copyright $\odot 2017$ by authors and Scientific Research Publishing Inc. This work is licensed under the Creative Commons Attribution International License (CC BY 4.0).

http://creativecommons.org/licenses/by/4.0/

\begin{abstract}
Based on theoretical analysis of the mechanism of enterprise technical capability structure, intellectual property risks and so on, this paper makes an empirical verification and puts forward the model of the enterprise technical capability matching degree's effect on intellectual property risk by contract control. Conclusion: the technical capability of the enterprise structure is divided into three dimensions: product development and manufacturing capabilities, applied generic technology and basic generic technology; intellectual property risk can be divided into personnel loss risk, and intellectual property theft risk related to cooperative innovation, intellectual property theft risk unrelated to cooperative innovation and Intellectual property investment risk; different dimensions of enterprise technological capability structure will reduce the risk of intellectual property rights, and the impact can be diversified; control mode can exert a mediating effect on the relationship between embedded influence on intellectual property risk.
\end{abstract}

\section{Keywords}

Intellectual Property Risk, Enterprise Technological Capability Structure, Contract Control

\section{Introduction}

With the rapid development and popularization of network information technology presently, updated speed of enterprise technology is expediting continuously. If enterprises still use self-sufficient management model, they will be faced with great business risk. Many countries all over the world have already explored highly mature mode of production-learning-research cooperation. 
Technologies from schools and scientific research institutions are transferred to the enterprises by cooperation, improving the innovation performance level constantly. Our country has begun to guide and promote production-learningresearch cooperation since 1992. However, it is still at the primary and exploration stage at present. It remains to be further explored how to achieve desired goals, especially the total integration of system and mechanism. The report of the 18th National Congress of CPC puts forward that the reform of scientific and technological system should be deepened continuously, scientific and technological achievements should be transformed into practical productive forces actively, perfect national innovation system should be set up, enterprises should be taken as the main body and the market should be as the guidance, and production-learning-research cooperation should be promoted positively. Scientific and technological innovation and production-learning-research cooperation have been raised to a new height. Therefore, the related theoretical research will be of practical guiding significance to practical activities. At present, the research on the existing cooperation focuses more on cooperative innovation mode, motivation, performance and other issues, which neglects the risk of cooperative innovation, especially for research on intellectual property risk. It's not systematic and comprehensive. This paper aims to study intellectual property risk in cooperative research from the perspective of management, so as to enrich and expand intellectual property risk from theory in the cooperation, thus laying the foundation for future research of intellectual property issues in cooperative innovation.

Based on the literature review, this paper firstly introduced the research status of technical capability structure, defined the structure of technical capability, and put forward the specific dimensions of technical capability structure; secondly, from the perspective of management, it put forward the specific dimensions of intellectual property risk in sharing of intellectual property; moreover, according to the literature research, it put forward control method in organizational cooperation-contract control. Finally, taking the contract control as intervening variable, this paper constructed the model of the enterprise technical capability matching degree's effect on intellectual property risk by contract control. By the questionnaire survey of enterprise technical structure matching degree, intellectual property risk and control methods, this paper adopts exploratory factor analysis, confirmatory factor analysis and structural equation model analysis method to check the model. The results of this study showed that: the technological capability of enterprises can be divided into three dimensions: product development and manufacturing capabilities, the applied generic technology capabilities and basic generic technology capabilities.

This research is divided into three steps: 1) theoretical basis and research assumptions; 2) empirical analysis; 3 ) research conclusions and future prospects.

\section{Theoretical Basis and Research Hypothesis}

\subsection{Enterprise Technical Capability Structure}

Enterprise technical capability structure is a kind of externalization of technolo- 
gical structure in terms of the enterprises' ability, which refers to the capacity distribution state overall demonstrated by three kinds of different technologies and their connections. This distribution is a systematic and structured capacity, which is explicitly displayed in the enterprise integration of internal and external resources, so as to develop the actual effect of product design and manufacturing technology (proprietary technology), the applied shared technology and basic generic technology [1].

According to the technical structure angle, the technical capability of the enterprise can be reflected by the specific technical type and its structure. Therefore, the enterprise technical capability structure can be divided into two dimensions of product design \& manufacturing technology capability and Generic technical capability, in which Generic technical capability can also be classified further as applied generic technical capability and basic generic technical capability.

Specifically, the technical know-how capability, which is called product design and manufacture capability, is the ability to create new knowledge and business output by means of learned knowledge and developmental learning. The ability of applied generic technology is a kind of practical absorptive ability to identify and understand the potential value of the application of theoretical knowledge by means of transformative learning, which focuses on the ability to transform and use knowledge. The ability of basic generic technology is a potential absorptive capacity to identify and understand the potential value of the underlying theory of knowledge through exploratory learning, which focuses on the ability to acquire and absorb knowledge of external basic theories.

\subsection{Enterprise Technological Capability Structure Matching}

As a concept of physics, matching refers to the phenomenon of two (or over two) systems or forms of motion interacting with each other through a variety of interactions. It can be seen from the connotation of matching that: the basic premise of matching is that some kind of association may occur in all the parties; the result of matching is that the attributes of each party will change (that is, the original property will be reduced and enlarged). In industry-university-research cooperation, enterprises, universities and research institutions may mutually interact and promote from each other, which can exert the amplified synergistic effect on technical capability structure of the enterprise itself, thus claiming that there is a cooperative relationship between the partners and the technical ability structure in the cooperation between enterprises and universities.

As the main participants in the cooperation of industry, university and research, enterprises and universities/scientific research are two diversified organizations, whose capability structure will have differences. Thus the matching degree of heterogeneity among organizations shall not be evaluated by the same evaluation system [2]. However, if the enterprise proprietary technology, the applied Generic Technology and Basic generic technology's basic dimensional activities can be effectively supported by the corresponding technical ability of 
universities and scientific research institutions, so that they can seek to effective operation, mutual integration and free combination, then it is the ideal matching relationship with partners in the cooperation of industry, university and research Institute in terms of technical capability structure of the enterprise itself [3].

This paper introduces the concept of the technological capability structure matching, which mainly aims to describe the state of the potential difference between the enterprise and the research party, so as to better study the risk of intellectual property rights in the process of cooperation.

\subsection{Intellectual Property Risk}

\subsubsection{Intellectual Property Risk Definition}

This paper argues that intellectual property risks in cooperative innovation refers to events and the possibility of a negative impact on the current or potential interests of holders of intellectual property rights produced by knowledge sharing mechanism and opportunistic behavior among partners in industry-university-research cooperative innovation, including the loss of intellectual property and the risk of failure to acquire intellectual property rights under a contractual agreement. As can be seen from the definition, industry university research cooperation innovation intellectual property risk refers to intellectual property owner risk, including the risk of intellectual property rights and the risk of innovation in the process of cooperation [4]. The reason of intellectual property risk lies in the opportunistic behavior of partners under knowledge sharing, which does not involve the distribution of benefits [5]. In the cooperative innovation of industry-university-research, universities, research institutions and enterprises may face the risk of intellectual property rights. However, the enterprise calls for intellectual property and personnel in view of cooperative innovation, and enterprises center on applied knowledge, which is not the main target of universities and scientific research institutions in innovative cooperation [6]. Therefore, scientific research institutions are facing more intellectual property risk when compared with enterprises and universities. The scope of research is defined in this paper as the intellectual property risks faced by universities and scientific research institutions in the sharing of intellectual property rights.

\subsubsection{Reasons for Intellectual Property Risk}

After understanding the concept of intellectual property risk, it is necessary to analyze the reasons for the formation of intellectual property risk, so as to deepen the understanding of the intellectual property risk discussed in this paper. It's believed that the main causes of intellectual property risk in the cooperation of industry, university and research institute can be analyzed from the three aspects of the behavior subject of intellectual property risk in cooperative innovation, the characteristics of the object and the process of cooperative operation:

1) Opportunistic behavior of both partners

Opportunistic behavior refers to the behavior of a party seeking its own interests by deception, including violence or distorted information, evade or failing to 
complete the promised things or obligations, and opportunistic behavior in cooperative enterprise is the main way leading to the loss of intellectual property. The cooperative innovation of industry-university-research cooperation is a kind of relatively loose organizational relationship, in which there is obvious opportunism between the intellectual property right supplier and the receiving party. Asymmetry of information, uncertainty in technological innovation and bounded rationality of man can cause incomplete contract, the mutual unequal dependence, participation motivation differences, uneven distribution of interests, or lack of integrity of the enterprise, which may prompt enterprises to take opportunistic behavior and find excuses for inadequate investment in intellectual property rights or theft or misappropriation of intellectual property rights in universities and research institutions, or even digging out the core talents.

2) Characteristics of knowledge itself

Knowledge can be the content of intellectual property, whose characteristics can cause intellectual property risk. Most of the knowledge in reality has the attribute of semi public product, which can cause knowledge disclosure paradox in the process of sharing and exchanging intellectual property rights, that is, universities and institutions of scientific research must disclose the real content of their intellectual property rights in order to enable enterprises to be more confident in deciding whether or not to cooperate. However, there is no need for enterprises to carry out knowledge transfer transactions after the main content of intellectual property rights has been exposed. The invisibility of knowledge leads to the loss of tacit knowledge in the process of dominance, which is also not easy to be detected; use of intellectual property and the value of uncertainty can cause uneven distribution of benefits, thus leading to opportunism behavior; effectiveness of fuzzy knowledge makes knowledge sharing is difficult to be evaluated and supervised, thus the opportunism behavior is difficult to be found and the possibility of the occurrence of intellectual property risks increases. The tacit knowledge is difficult to be applied as the text, which can hardly be protected by intellectual property rights, thus intensifying the promptness of enterprises to steal tacit knowledge.

3) Knowledge sharing and knowledge spillover

Cross organizational knowledge sharing refers to the process of exchanging explicit knowledge and tacit knowledge between knowledge owners and their partners, which includes two processes of knowledge transfer and absorption. The content of intellectual property is knowledge, and the essence of knowledge sharing is knowledge sharing. In the process of industry-university-research innovative cooperation, enterprises, universities and scientific research institutions must share knowledge and utilize the original intellectual property rights and phased results of colleges, universities and scientific research institutions. For example, sharing explicit knowledge through the words or language; sharing tacit knowledge through regular academic research, mentoring, joint development projects and face-to-face communication. However, the flow of knowledge in the organization will lose proprietary intellectual property, which can provide intel- 
lectual property theft opportunities for cooperative enterprises; meanwhile, in the process of cooperation, $\mathrm{R} \& \mathrm{D}$ personnel exchanges will inevitably cause knowledge spillovers, thus directly causing intellectual property loss. Semi public goods attribute of knowledge causes that knowledge sharing does not require the knowledge provider to give up the ownership of knowledge, but emphasizes the sharing of knowledge with the participants. Therefore, this paper argues that once the members of the cooperative innovation open and share their intellectual property rights, they may be subject to the risk of intellectual property rights that other partners do not comply with the agreement in the process of intellectual property sharing. As is often the case, the mutual enthusiasm is very high at the beginning of the industry-university-research cooperation, but finally it fails. The reason is that intellectual property risk is a critical issue.

\subsubsection{Dimensional Analysis on the Intellectual Property Risk in the Industry-University-Research Cooperative Innovation}

Intellectual property risk in this paper includes the original risk loss of intellectual property risk and the risk of failure to acquire intellectual property rights under a contractual agreement. Based on the theoretical research and practical experience, this paper holds that intellectual property risks in cooperative innovation can get lesson from Zhang Keying, Guo Wei, Chen Weiliang (2008)'s opinions, including intellectual property loss risk and intellectual property investment risk [5]. However, intellectual property loss risk can get lesson from $\mathrm{Su}$ Shibin, Huang Ruihua (2009)'s opinions, including personnel turnover risk, risk of theft of intellectual property related to cooperative innovation and intellectual property leakage unrelated to cooperative innovation [7]. Although the loss of personnel will result in the loss of intellectual property rights which are not related to the cooperation innovation and the risk of theft of intellectual property rights which have nothing to do with the cooperation innovation, the three sides have inclusion relation [6]. However, according to this paper, the staff is an important carrier of knowledge, which is a crucial role in the intellectual property risk and can be separated into a dimension. Therefore, it's believed that the intellectual property risks in cooperative innovation include four dimensions: personnel turnover risk, risk of theft of intellectual property related to cooperative innovation, intellectual property leakage unrelated to cooperative innovation and Intellectual property investment risk.

\subsubsection{The Relationship between the Technical Capability Structure Matching and the Intellectual Property Risk in the Industry-University-Research Cooperation}

According to above analysis on the causes and dimensions of intellectual property risk, the conclusion can be drew that long-term cooperation mechanisms shall be constructed to solve the problem of intellectual property risk in the cooperation. As mentioned earlier, the long-term cooperation mechanism is a good match among the main cooperation capability structure, cooperative behavior and cooperative performance. In the current Chinese scenario featured by low level of quality, technical cooperation and cooperative innovation efficiency, 
the root cause lies in our country's weak applied industrial generic technology capability at the present stage. The structure of enterprise technological capability defines the nature of the problems that must be solved in the process of innovation, which determines the technical supply orientation of the cooperation of industry-university-research institute. Therefore, forming the supply mechanism of cooperative innovation to establish common technology and strengthening the enterprise's applied common technical capability construction through taking the technology capability structure as direction enterprise technology capability, is the key and breakthrough of the cooperation mechanism to enhance cooperation and innovation capability and build long-term stable cooperative mechanism. Therefore, the technical ability structure matching in the industry university research cooperation will help to improve the continuity and stability of the cooperation of industry-university-research institute, thus reducing the risk of intellectual property in the process of cooperation.

\subsection{Contract Control}

Formal contracts are derived from two basic assumptions of transaction cost theory on human nature: bounded rationality and opportunism (Williamson, 1996b). According to the transaction cost theory, the enterprise can not make clear predictions of the situation before the transaction due to the limited rationality, so the opportunistic behavior may breed in the transaction process in the lack of effective governance. In order to make the transaction with potential risk be carried out smoothly, the two sides need to establish credible commitments before the transaction. The formal contract control is such a credible commitment. (Williamson, 1996a) [8].

\subsubsection{The Contractual Incompleteness}

Williamson (Oliver E., 2002,) believes that the reasons of the contractual incompleteness come mainly from the uncertainty of transactions and the limited rationality of human beings [9]. Uncertainty can be divided into two categories: primary and secondary type. The former refers to the random situation and the latter refers to the lack of information in communication, that is, one can hardly know others' decisions and plans in making a decision. These two types of uncertainty are not involved in intentional camouflage, concealment or distortion of information, etc.. However, the opportunistic behavior such as camouflage, concealment or distortion of information will appear once the two sides of the transaction have a bilateral relationship due to the specific investment. Therefore, Williamson believes that the third type of uncertainty should be recognized, that is, the uncertainty caused the parties' opportunistic behavior. In addition, limited rationality makes people lack sufficient information and the capability to design a comprehensive contract. It is hard to foresee all possible states at the time of signing when facing the complex and uncertain world; even if it can be foreseen, it will be difficult to describe all possible states by precise language, let alone make specific provisions for every circumstance, responsibility and authority. The gaps and omissions may inevitably exist in the design of 
the contract since people are naturally limited by reason. (Oliver E, Williamson, 2001).

\subsubsection{Matching and Contract of Enterprise Technical Capability Structure}

As for Das \& Teng (1996), the longer the cooperation between the two sides, the partners will have a higher degree of confidence in the quality and motivation of the other party [10]. It is not necessary to implement a high formal control, which in turn will cause resentment. However, some scholars believe that longterm cooperation will be more conducive to the development of good feelings between the two sides, which is easier to reach a consensus on the rules and systems, thus helping enterprises follow the voluntary action of colleges, universities and scientific research institutions. The technical capability of the enterprise structure can help to build a long-term cooperation mechanism [3]. Therefore, it can be safely said that, no matter the technological capabilities of enterprises can promote or inhibit the formation of structure or contract control behavior, technical structural capability matching can impact intellectual property risk through contract control.

\subsubsection{Contract and Risk}

Transaction cost theory holds that the goal of cooperative control is to prevent the occurrence of speculative behavior through a series of control measures, thus ultimately reducing the transaction costs. Appropriate control is an effective way to solve the intellectual property risks of cooperative innovation, and good operation of cooperative innovation control mainly depends on the mutual contractual restriction and mutual values and cultural constraints [11].

\subsection{Research Model}

To sum up, this paper constructs the model of the influence of the matching of enterprise's technological capability on the intellectual property risk as follows. Taking contract control as the intervening variable, it deeply explores whether various dimensions of enterprise technological capability structure can impact specific dimensions of intellectual property risks and the relevant mechanism. The research model is shown in Figure 1.

\section{Research Design}

\subsection{Sample Selection and Data Sources}

This study stays in the cross organizational level. Since it relates to the inter organizational technical capability matching, intellectual property risk and contract control etc. relevant data can not be obtained through public data, thus questionnaire is adopted for data collection. Considering the convenience and representativeness of the data obtained, this study adopts the Questionnaire Star sample service to conduct empirical study on enterprises in Beijing, Shenzhen, Guangzhou and other cities. Respondents must be the enterprise personnel with relevant innovative experience. In view of the professional content of the study, 


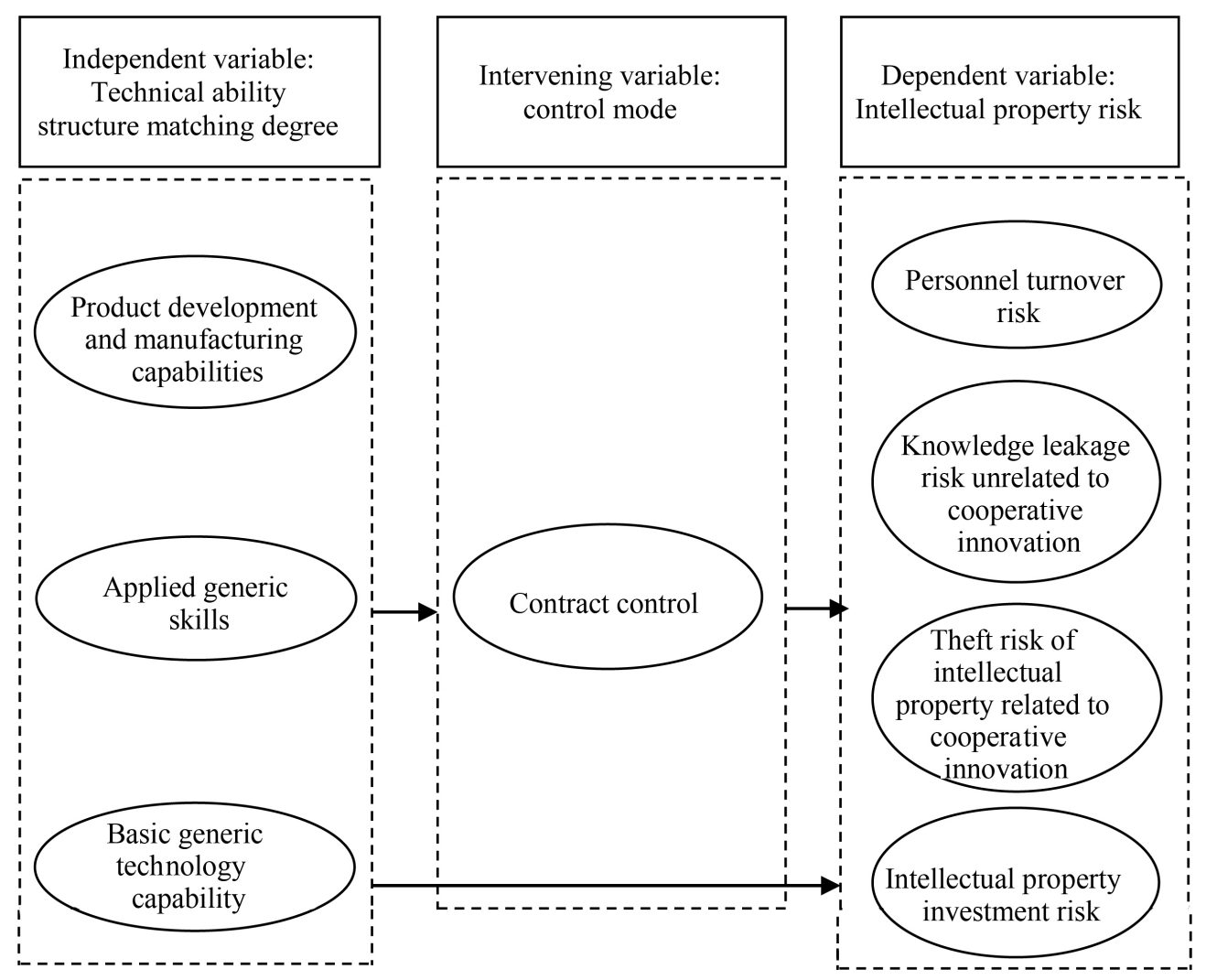

Figure 1. Research model.

only the middle and upper management staff of enterprises are investigated. Due to the nature and the content of the work and other factors, they have a deep understanding of the technical capability structure matching, contract control and intellectual property risk.

\subsection{Variable Definition and Measurement}

\subsubsection{Enterprise Technical Capability Structure [1]}

Proprietary technical capability refers to the capability of the enterprise to transform the technology into the product level.

1) Product design and development capabilities: have the capability to develop a series of product design (have product platform technical capabilities), which is reflected in adjusting the product modules and architecture by using existing mature platform technology, to design and develop a series of product models.

2) Product production \& assembly capability: have the capability to convert the product model into a product, which is reflected in producing and assembling products by mature technology based on the product model.

The application of generic technology capabilities refers to enterprises' ability of integrated utilization and add-on development in the process of platform technology diffusion and optimization; it's mainly embodied in the "technical" level of activity.

1) The optimization capability of frontier technology: the optimization and deepening ability for the frontier technology. It's also reflected in add-on devel- 
opment and innovation of the existing "technology paradigm", "technology track" and "technology platform", thus forming the dominant platform technology (and standards).

2) Platform technology integration capability: have the ability to integrate and utilize the dominant (emerging) platform technologies, which is embodied in the introduction of the world's leading platform technology, utilizing and internalizing.

Basic generic technology capability is the capability of the enterprise in the process of dealing with the interaction between science and technology. The technical transformation capability of Science:

1) Scientific technology transformation ability: have the ability to develop scientific principles into cutting-edge technologies, which is embodied as combining scientific principles with market demands, and establishing a new "technology paradigm", "technology trajectory" and "technology platform".

2) Technology scientific exploration capability: have the ability to capture the frontier science and technology and probe its scientific principle; which is embodied exploring and researching frontier cutting-edge technology principle.

To sum up, the measurement items are shown in Table 1.

\subsubsection{Intellectual Property Intellectual Property Risk}

Quantitative analysis on the intellectual property risk is quite few, this paper uses for reference measurement of core competence and technology loss risk when inter firm relationship capital influences core competence and technology drain put forward by Helerue (2004) [12]. Zhang Keying, Huang Ruihua (2007)'s scale on loss risk and investment risk of intellectual property [5]. And Xing Zizheng. Huang Ruihua, Wang Zhong (2008)'s measurement of knowledge loss risk in study on the relationship between knowledge loss and knowledge protection in cooperation [13]. Based on the four dimensions of intellectual property risk, the paper develops the intellectual property risk scale composing of eleven items. The specific measurement items are shown in Table 2.

\subsubsection{Contract Control}

Formal control refers to utilizing formal rules, systems and policies to monitor other party's behavior based on formal contract. Jap \& Ganesan (2000) measured formal control by the following indicators: our mutual relationship is mainly managed by a written contract [14]. And we can communicate well with the other part only when things and all the details very carefully written. Generally, we have formed tacit understanding to complete the task without fully expressing. Gulati \& Singh (1998) adopted indicators: the two sides have jointly developed and formed a perfect contract, a clear solution to the dispute and conflict between the two sides has been established in cooperation [15]. Therefore, based on the research of the above two scholars, this paper adopts 3 items to measure the contract control mode between universities, research institutions and enterprises. The specific measurement items are shown in Table 3. 
Table 1. Technological capability structure matching degree gauge.

\begin{tabular}{|c|c|}
\hline & Measure item \\
\hline \multirow{8}{*}{$\begin{array}{c}\text { Product } \\
\text { development } \\
\text { and } \\
\text { manufacturing } \\
\text { capabilities }\end{array}$} & $\begin{array}{l}\text { Cooperative university/Scientific research institutions can effectively help us } \\
\text { collect market intelligence }\end{array}$ \\
\hline & $\begin{array}{l}\text { Cooperative university/Scientific research institutions can effectively help us } \\
\text { understand customer preferences }\end{array}$ \\
\hline & $\begin{array}{l}\text { Cooperative university/Scientific research institutions can effectively help us } \\
\text { to convert market information into product concepts }\end{array}$ \\
\hline & $\begin{array}{l}\text { Cooperative university/Scientific research institutions can effectively help us } \\
\text { to introduce production lines }\end{array}$ \\
\hline & $\begin{array}{l}\text { Cooperative university/Scientific research institutions can effectively help us } \\
\text { transform production equipment }\end{array}$ \\
\hline & $\begin{array}{l}\text { Cooperative university/Scientific research institutions can help us to optimize } \\
\text { production process and reduce production cost }\end{array}$ \\
\hline & $\begin{array}{l}\text { Cooperative university/Scientific research institutions can effectively help us } \\
\text { to coordinate and integrate upstream and downstream enterprise technology } \\
\text { and product development }\end{array}$ \\
\hline & $\begin{array}{l}\text { Cooperative university/Scientific research institutions can effectively help us } \\
\text { to build supply chain or industrial chain alliance }\end{array}$ \\
\hline \multirow[t]{5}{*}{$\begin{array}{l}\text { Applied generic } \\
\text { skills }\end{array}$} & $\begin{array}{l}\text { Cooperative university/Scientific research institutions can effectively help us } \\
\text { to collect market oriented basic technical information }\end{array}$ \\
\hline & $\begin{array}{l}\text { Cooperative university/Scientific research institutions can effectively help us } \\
\text { to carry out the add-on development of basic technology }\end{array}$ \\
\hline & $\begin{array}{l}\text { Cooperative university/Scientific research institutions can effectively help us } \\
\text { to refine the basic theory and the method for promotion }\end{array}$ \\
\hline & $\begin{array}{l}\text { Cooperative university/Scientific research institutions can effectively } \\
\text { cooperate with us in basic research }\end{array}$ \\
\hline & $\begin{array}{l}\text { Cooperative university/Scientific research institutions can effectively carry out } \\
\text { exploratory projects with us }\end{array}$ \\
\hline \multirow[t]{3}{*}{$\begin{array}{l}\text { Basic generic } \\
\text { technology } \\
\text { capability }\end{array}$} & $\begin{array}{l}\text { Cooperative university/Scientific research institutions can effectively help us } \\
\text { to explore new scientific principles }\end{array}$ \\
\hline & $\begin{array}{l}\text { Cooperative university/Scientific research institutions can effectively help us } \\
\text { to develop innovative research and research fields }\end{array}$ \\
\hline & $\begin{array}{l}\text { Cooperative university/Scientific research institutions can effectively help us } \\
\text { to introduce high-level talents }\end{array}$ \\
\hline
\end{tabular}

\section{Empirical Analysis and Results}

\subsection{Descriptive Statistics}

The questionnaires are begun to handing out on January 21, 2017 in this study, lasting nearly one month. 455 questionnaires were returned in total. Since filtering problems are included in the survey, after invalid questionnaires which are filtered out, leak filled and obviously perfunctory are eliminated, 378 effective questionnaires are obtained and the effective rate is $83 \%$.

This paper carried out frequency statistics and percentage in the total number on gender, occupation and industry-university-research cooperation mode in the personal information. 
Table 2. Intellectual property riskgauge.

\begin{tabular}{|c|c|}
\hline & Measure item \\
\hline $\begin{array}{l}\text { Personnel } \\
\text { turnover risk }\end{array}$ & $\begin{array}{l}\text { Cooperation leads to the possibility that some of our key technology } \\
\text { employees or managers are being selected out. } \\
\text { Cooperation causes the possibility of some of our key technical personnel } \\
\text { or managers to disclose their technical secrets in various forms. }\end{array}$ \\
\hline $\begin{array}{l}\text { Theft risks of } \\
\text { intellectual } \\
\text { property related } \\
\text { to cooperative } \\
\text { innovation }\end{array}$ & $\begin{array}{l}\text { In the process of cooperation, we have demonstrated our key skills to } \\
\text { cooperative universities/research institutions, but the possibility of a loss } \\
\text { of our core knowledge is very high. } \\
\text { As a result of cooperation, our technical secrets (process flow, product } \\
\text { formulation, technical drawings, etc.) are likely to be stolen } \\
\text { Cooperation will make our technical know-how often illegally copied } \\
\text { (such as visiting, practice or mentoring) }\end{array}$ \\
\hline $\begin{array}{l}\text { Knowledge leakage } \\
\text { risk unrelated to } \\
\text { cooperative } \\
\text { innovation }\end{array}$ & $\begin{array}{l}\text { We are worried that the cooperative universities/research institutions will } \\
\text { adopt some other means to grab the key knowledge beyond our shared } \\
\text { agreement. } \\
\text { Cooperation will enable cooperative universities/research institutions to } \\
\text { penetrate we did not intend to disclose technical know-how. } \\
\text { We share our knowledge unconsciously since cooperative } \\
\text { universities/research institutions seek to informal } \\
\text { communication with us. }\end{array}$ \\
\hline $\begin{array}{l}\text { Intellectual } \\
\text { property } \\
\text { investment risk }\end{array}$ & $\begin{array}{l}\text { Cooperative universities/research institutions fail to transfer their skills } \\
\text { and knowledge to us in accordance with the provisions. } \\
\text { Cooperative universities/research institutions keep silent, uncooperative } \\
\text { and over protected, which make us fail to receive the correct knowledge. } \\
\text { In the process of cooperation, the cooperative universities/research } \\
\text { institutions will pass some false information and knowledge etc. }\end{array}$ \\
\hline
\end{tabular}

Table 3. Contract control gauge.

Measure item

We can cooperate smoothly only when the details of the cooperation are stipulated by the cooperation agreement.

Contract Overall, a cooperation agreement signed by the two sides is the most control powerful tool to constrain each other's behavior.

We have established a clear system and approach to resolve disputes and conflicts between the two sides in our cooperation.

According to the Table 4: there are 231 males, accounting for $61.1 \%, 147 \mathrm{fe}$ males, accounting for $38.9 \%$, the number of men transcend that of women; middle managers take a large part, accounting for 59.3\%; followed by the top management staff, accounting for 37\%; grassroots managers account for only $3.7 \%$; in terms of industry-university-research cooperation, cooperation and development accounts for $81.5 \%$; then the joint research base, joint research project account for over $60 \%$. Industry Technology Alliance accounts for $31.5 \%$.

\subsection{Reliability and Validity Analysis}

In order to ensure the reliability and stability of the questionnaire, we must 
Table 4. Descriptive statistics.

\begin{tabular}{cccc}
\hline & & Frequency & Percentage \\
\hline \multirow{2}{*}{ Gender } & Male & 231 & 61.1 \\
& Female & 147 & 38.9 \\
& Senior management staff & 140 & 37.0 \\
Position & Middle manager & 224 & 59.3 \\
& First Line Managers & 14 & 3.7 \\
& Cooperative development & 308 & 81.5 \\
Cooperative mode of & Joint research projects & 238 & 63.0 \\
industry university & Scientific research base & 245 & 64.8 \\
research cooperation & co-foundation & 196 & 51.9 \\
& Set up R \& D entities & 119 & 31.5 \\
\hline
\end{tabular}

analyze the reliability of the questionnaire. We usually adopt $\alpha$ coefficient (Cronbach $\alpha$ coefficient) to measure the reliability of the questionnaire. The greater the alpha coefficient, the higher the reliability of the questionnaire, and the higher the credibility and stability of the questionnaire. With the in-depth study, scholars' requirements for the reliability of the questionnaire have become increasingly high. In the early research, questionnaire reliability having the alpha coefficient higher than 0.5 is acceptable, those of over 0.7 are excellent. In recent study, the alpha coefficient of 0.6 is regarded as the acceptable line. When alpha coefficient is greater than 0.8 or even over 0.9 , the questionnaire can be deemed to have excellent reliability.

It can be seen from Table 5: structure matching scale and the following Cronbach $\alpha$ coefficient is greater than 0.7 , intellectual property risk scale and the following 4 Cronbach $\alpha$ coefficients are greater than 0.7 , Cronbach $\alpha$ coefficient in the control Cronbach scale is 0.810 , which is over 0.8. In this designed questionnaire, according to the recovery data, the reliability of 3 scales reached excellent reliability.

Under the condition of standard reliability level, in order to ensure the questionnaire set can effectively reflect the real meaning of our variables, we also need to continue to analyze the validity of the questionnaire. The validity is an important index to reflect the validity of the questionnaire. This paper adopts the method of factor analysis to test the validity of the questionnaire. Before the factor analysis, we must first determine whether questionnaire is suitable for factor analysis, which requires to adopts SPSS to calculate the KMO value and Bartlett sphere test, if the KMO value is greater than 0.7, P value is less than 0.05 , then the questionnaire is suitable for factor analysis.

According to the Tables 6-8: the KMO values of each table were greater than 0.7 , and the $\mathrm{P}$ values were all lower than 0.05 , which was consistent with the factor analysis of the factor analysis of the two conditions. The following figure and table shows the example of verification technology structure matching model. The results show that the model is validated by confirmatory factor analysis. 
Table 5. Reliability statistics.

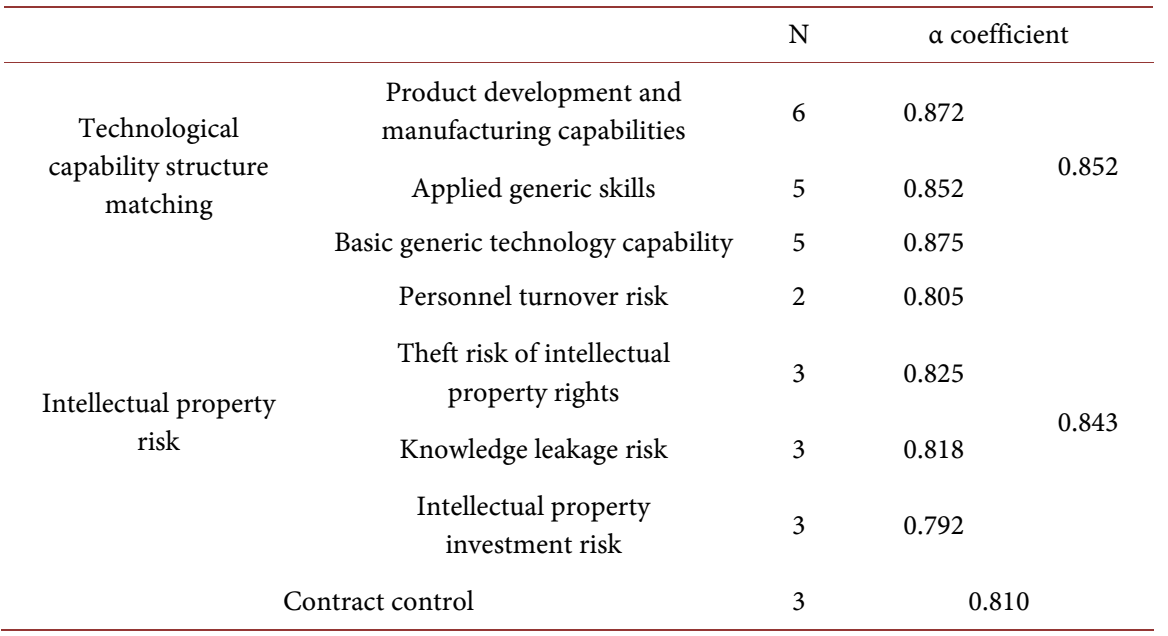

Table 6. Technological capability structure matching KMO and Bartlett test.

\begin{tabular}{ccc}
\hline \multicolumn{2}{c}{ Adopt KMO Sampling adequacy } & 0.881 \\
\hline & Approximate chi square & 2819.879 \\
Bartlett sphericity test & Freedom degree & 120 \\
& Significance & 0.000 \\
\hline
\end{tabular}

Table 7. Intellectual property risk KMO and Bartlett test.

\begin{tabular}{ccc}
\hline \multicolumn{2}{c}{ Adopt KMO Sampling adequacy } & 0.801 \\
\hline & Approximate chi square & 1677.824 \\
Bartlett sphericity test & Freedom degree & 55 \\
& Significance & 0.000 \\
\hline
\end{tabular}

Table 8. Contract control KMO and Bartlett test.

\begin{tabular}{ccc}
\hline \multicolumn{2}{c}{ Adopt KMO Sampling adequacy } & 0.713 \\
\hline & Approximate chi square & 389.301 \\
Bartlett sphericity test & Freedom degree & 3 \\
& Significance & 0.000 \\
\hline
\end{tabular}

It is shown in Figure 2, standard estimated values of each question at the corresponding latitude are all greater than 0.6 , suggesting that every question can explain the latitude represented by itself well. As can be seen from Table 9, the metrics of the evaluation model are well fitted, suggesting measure has structure validity. The value $\mathrm{P}$ is 0.258 , greater than 0.05 , which indicates that the mode is acceptable, and is approved by confirmatory factor analysis. And there is a positive correlation between modified paths and independent variables, consistent with the actual situation, so the correction is effective.

\subsection{Model Fitting Results}

In this paper, the initial model is modified, and the corresponding fitting index 


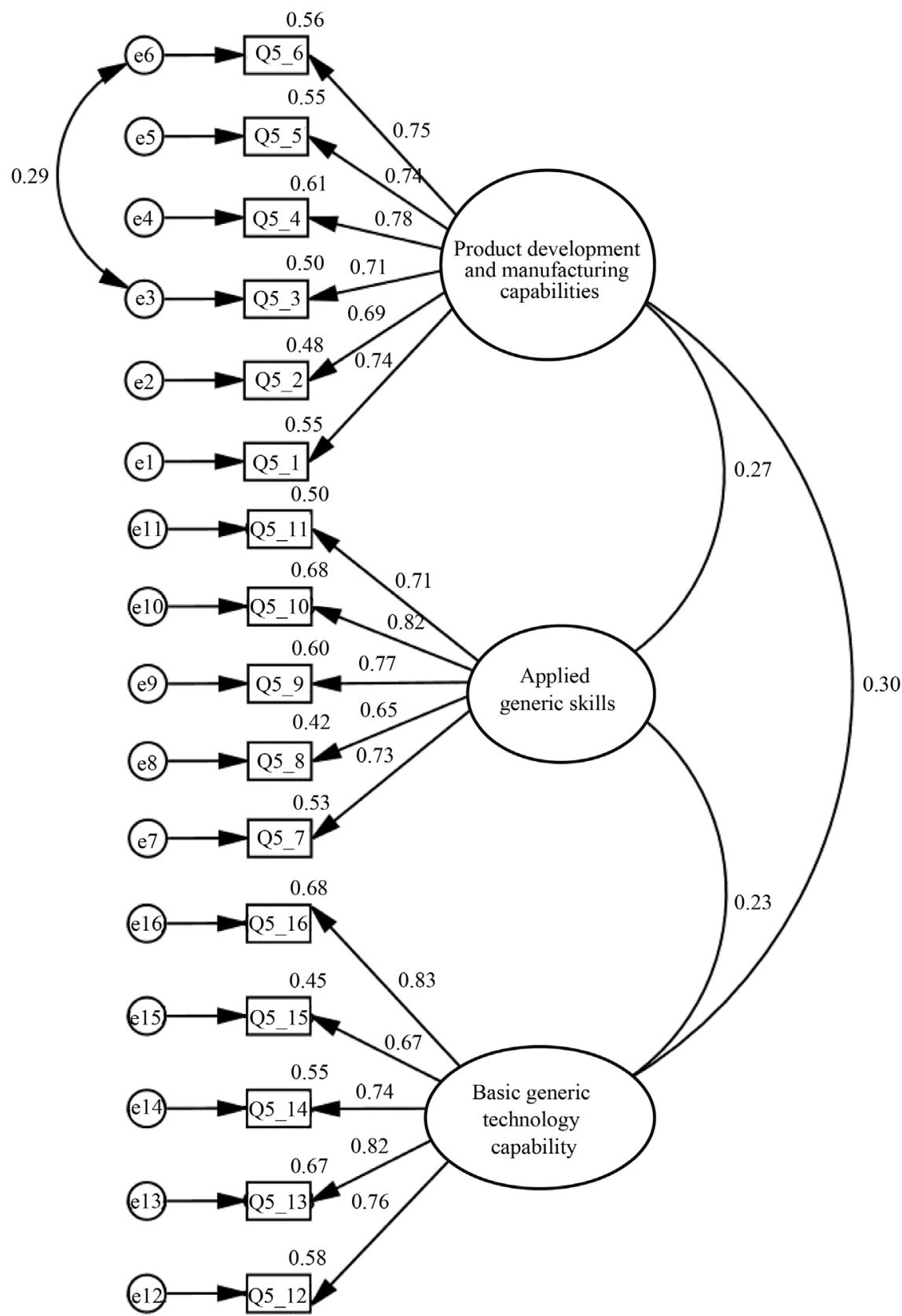

Figure 2. Technological capability structure matching confirmatory factor analysis.

is indicated in the Figure 3 and Table 10. It can be seen that index RMR and SRMR, which evaluate the conciseness of the model, be-come the desired value after revision. In addition, the value $\mathrm{P}$ evaluating whether the model can be accepteda is 0.067 , greater than 0.05 , comfirm to the standard, so the modified model is acceptable. And there is a positive correlation between modified paths and independent variables, consistent with the actual situation, so the correction is effective.

\subsection{Hypothesis Test Results (Path Coefficients of Variables)}

It can be seen from the above Table 11: 


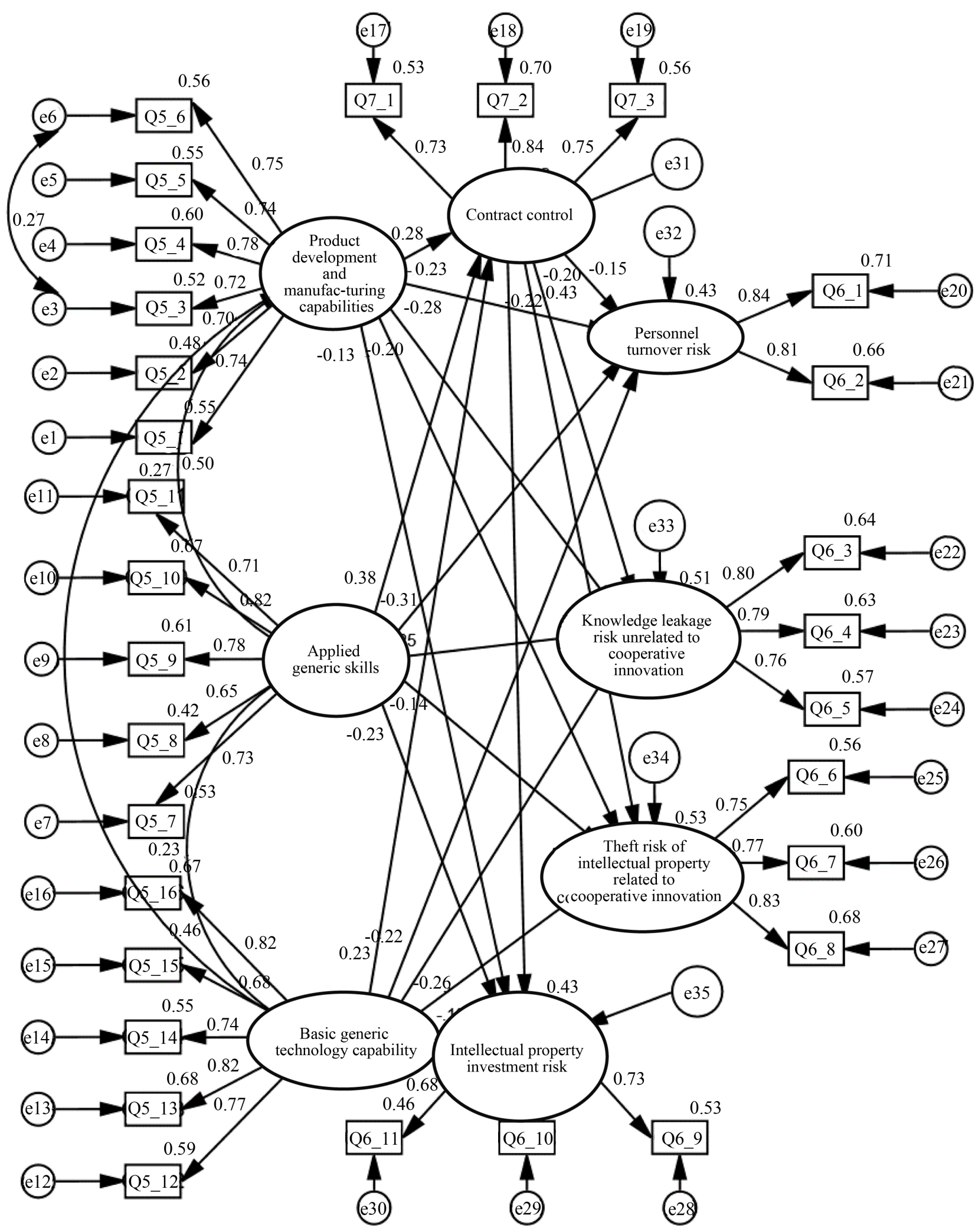

Figure 3. Model fitting results.

The standardized path coefficient of product development and manufacturing capabilities, applied generic technical capability, basic generic technical capacity 
Table 9. The fitting index of technological capability structure matching confirmatory factor analysis.

\begin{tabular}{cccc}
\hline Statistic value & $\begin{array}{c}\text { Adaptive criteria or } \\
\text { critical values }\end{array}$ & Test result & Fitting judgment \\
\hline$\chi^{2}$ & & 108.789 & \\
$\mathrm{df}$ & $1<\chi^{2} / \mathrm{df}<2$ & 100 & Yes \\
$\chi^{2} / \mathrm{df}$ & $>0.05$ & 1.088 & Yes \\
$\mathrm{P}$ & $<0.05$ & 0.258 & \\
$\mathrm{RMR}$ & $<0.05$ & 0.022 & Yes \\
SRMR & $>0.90$ & 0.030 & Yes \\
GFI & $>0.90$ & 0.965 & Yes \\
AGFI & $>0.90$ & 0.953 & Yes \\
NFI & $>0.90$ & 0.962 & Yes \\
IFI & $>0.90$ & 0.997 & Yes \\
CFI & $<0.08$ & 0.997 & Yes \\
RMSEA & & 0.015 & \\
\hline
\end{tabular}

Table 10. Model fitting index.

\begin{tabular}{cccc}
\hline Statistical test & $\begin{array}{c}\text { Adaptive criteria or critical } \\
\text { values }\end{array}$ & Test result data & Model fit judgment \\
\hline$\chi^{2}$ & & 424.209 & \\
$\mathrm{df}$ & $1<\chi^{2} / \mathrm{df}<2$ & 382 & \\
$\chi^{2} / \mathrm{df}$ & $>0.05$ & 1.110 & Yes \\
$\mathrm{P}$ & $<0.05$ & 0.067 & Yes \\
RMR & $<0.05$ & 0.030 & Yes \\
SRMR & $>0.90$ & 0.032 & Yes \\
GFI & $>0.90$ & 0.932 & Yes \\
AGFI & $>0.90$ & 0.917 & Yes \\
NFI & $>0.90$ & 0.927 & Yes \\
IFI & $>0.90$ & 0.992 & Yes \\
CFI & $<0.08$ & 0.992 & Yes \\
RMSEA & & 0.017 & \\
\hline
\end{tabular}

against personnel loss risk are respectively $-0.231,-0.311,-0.215$, the corresponding $\mathrm{P}$ values over 0.05 level is significant, indicating that the product development and manufacturing capabilities, applied generic technical capability, basic generic technology capability can exert a significant negative effect on personnel turnover risk, thus $\mathrm{Hla}, \mathrm{H} 1 \mathrm{~b}, \mathrm{H} 1 \mathrm{c}$ are right.

Standardized path coefficient of Product development and manufacturing capabilities, Applied generic skills, Basic generic technology capability against intellectual property theft risk is respectively $-0.280,-0.253,-0.259$, the corresponding $\mathrm{P}$ values over 0.05 level is significant, indicating that the product development and manufacturing capabilities, applied generic technical capability, 
Table 11. Model path analysis of modified structural equation.

\begin{tabular}{|c|c|c|c|c|c|c|c|c|c|}
\hline Hypothesis & & & & Estimate & $\begin{array}{l}\text { Standardized } \\
\text { Estimate }\end{array}$ & S.E. & C.R. & $\mathrm{P}$ & Test results \\
\hline & Contract control & $<---$ & $\begin{array}{l}\text { Product development } \\
\text { and manufacturing } \\
\text { capabilities }\end{array}$ & 0.358 & 0.284 & 0.074 & 4.866 & $* * *$ & Forming \\
\hline & Contract control & $<---$ & Applied generic skills & 0.294 & 0.383 & 0.046 & 6.409 & $* * *$ & Forming \\
\hline & Contract control & $<---$ & $\begin{array}{l}\text { Basic generic technology } \\
\text { capability }\end{array}$ & 0.190 & 0.234 & 0.045 & 4.192 & $* * *$ & Forming \\
\hline $\mathrm{H} 1 \mathrm{a}$ & $\begin{array}{l}\text { Personnel turnover } \\
\text { risk }\end{array}$ & $<---$ & $\begin{array}{l}\text { Product development } \\
\text { and manufacturing } \\
\text { capabilities }\end{array}$ & -0.429 & -0.231 & 0.115 & -3.727 & *** & Forming \\
\hline $\mathrm{H} 1 \mathrm{~b}$ & $\begin{array}{l}\text { Personnel } \\
\text { turnover risk }\end{array}$ & $<---$ & Applied generic skills & -0.353 & -0.311 & 0.075 & -4.730 & $* * *$ & Forming \\
\hline $\mathrm{H} 1 \mathrm{c}$ & $\begin{array}{l}\text { Personnel } \\
\text { turnover risk }\end{array}$ & $<---$ & $\begin{array}{l}\text { Basic generic technology } \\
\text { capability }\end{array}$ & -0.258 & -0.215 & 0.069 & -3.730 & $* * *$ & Forming \\
\hline $\mathrm{H} 2 \mathrm{a}$ & $\begin{array}{l}\text { Theft risks of } \\
\text { intellectual } \\
\text { property rights }\end{array}$ & $<---$ & $\begin{array}{l}\text { Product development } \\
\text { and manufacturing } \\
\text { capabilities }\end{array}$ & -0.591 & -0.280 & 0.124 & -4.778 & $* * *$ & Forming \\
\hline $\mathrm{H} 2 \mathrm{~b}$ & $\begin{array}{l}\text { Theft risks of } \\
\text { intellectual } \\
\text { property rights }\end{array}$ & $<---$ & Applied generic skills & -0.325 & -0.253 & 0.078 & -4.174 & $* * *$ & Forming \\
\hline $\mathrm{H} 2 \mathrm{c}$ & $\begin{array}{l}\text { Theft risks of } \\
\text { intellectual } \\
\text { property rights }\end{array}$ & $<---$ & $\begin{array}{l}\text { Basic generic technology } \\
\text { capability }\end{array}$ & -0.351 & -0.259 & 0.075 & -4.677 & *** & Forming \\
\hline $\mathrm{H} 3 \mathrm{a}$ & $\begin{array}{l}\text { Knowledge } \\
\text { leakage risk }\end{array}$ & $<---$ & $\begin{array}{l}\text { Product development } \\
\text { and manufacturing } \\
\text { capabilities }\end{array}$ & -0.446 & -0.201 & 0.127 & -3.500 & $* * *$ & Forming \\
\hline $\mathrm{H} 3 \mathrm{~b}$ & $\begin{array}{l}\text { Knowledge } \\
\text { leakage risk }\end{array}$ & $<---$ & Applied generic skills & -0.191 & -0.141 & 0.079 & -2.399 & 0.016 & Forming \\
\hline $\mathrm{H} 3 \mathrm{c}$ & $\begin{array}{l}\text { Knowledge } \\
\text { leakage risk }\end{array}$ & $<---$ & $\begin{array}{l}\text { Basic generic technology } \\
\text { capability }\end{array}$ & -0.258 & -0.181 & 0.078 & -3.311 & $* * *$ & Forming \\
\hline $\mathrm{H} 4 \mathrm{a}$ & $\begin{array}{l}\text { Intellectual property } \\
\text { investment risk }\end{array}$ & $<---$ & $\begin{array}{l}\text { Product development } \\
\text { and manufacturing } \\
\text { capabilities }\end{array}$ & -0.214 & -0.126 & 0.102 & -2.103 & 0.035 & Forming \\
\hline $\mathrm{H} 4 \mathrm{~b}$ & $\begin{array}{l}\text { Intellectual property } \\
\text { investment risk }\end{array}$ & $<---$ & Applied generic skills & -0.238 & -0.231 & 0.067 & -3.577 & $* * *$ & Forming \\
\hline \multirow[t]{5}{*}{$\mathrm{H} 4 \mathrm{c}$} & $\begin{array}{l}\text { Intellectual property } \\
\text { investment risk }\end{array}$ & $<---$ & $\begin{array}{l}\text { Basic generic technology } \\
\text { capability }\end{array}$ & -0.347 & -0.320 & 0.066 & -5.270 & $* * *$ & Forming \\
\hline & $\begin{array}{l}\text { Personnel } \\
\text { turnover risk }\end{array}$ & $<---$ & Contract control & -0.225 & -0.153 & 0.110 & -2.045 & 0.041 & Forming \\
\hline & $\begin{array}{l}\text { Theft risks of } \\
\text { intellectual } \\
\text { property rights }\end{array}$ & $<---$ & Contract control & -0.340 & -0.203 & 0.118 & -2.884 & 0.004 & Forming \\
\hline & $\begin{array}{l}\text { Knowledge } \\
\text { leakage risk }\end{array}$ & $<--$ & Contract control & -0.755 & -0.428 & 0.134 & -5.651 & $* * *$ & Forming \\
\hline & $\begin{array}{l}\text { Intellectual property } \\
\text { investment risk }\end{array}$ & $<---$ & Contract control & -0.296 & -0.220 & 0.100 & -2.942 & 0.003 & Forming \\
\hline
\end{tabular}


basic generic technology capability can exert a significant negative effect on personnel turnover risk, thus $\mathrm{H} 2 \mathrm{a}, \mathrm{H} 2 \mathrm{~b}, \mathrm{H} 2 \mathrm{c}$ are right.

The standardized path coefficient of product development and manufacturing capabilities, applied generic technical capability, basic generic technical capacity against personnel loss risk are respectively $-0.201,-0.141,-0.181$, the corresponding $\mathrm{P}$ values over 0.05 level is significant, indicating that the product development and manufacturing capabilities, applied generic technical capability, basic generic technology capability can exert a significant negative effect on personnel turnover risk, thus $\mathrm{H} 3 \mathrm{a}, \mathrm{H} 3 \mathrm{~b}, \mathrm{H} 3 \mathrm{c}$ are right.

The standardized path coefficient of product development and manufacturing capabilities, applied generic technical capability, basic generic technical capacity against personnel loss risk are respectively $-0.126,-0.231,-0.320$, the corresponding $\mathrm{P}$ values over 0.05 level is significant, indicating that the product development and manufacturing capabilities, applied generic technical capability, basic generic technology capability can exert a significant negative effect on personnel turnover risk, thus $\mathrm{H} 4 \mathrm{a}, \mathrm{H} 4 \mathrm{~b}, \mathrm{H} 4 \mathrm{c}$ are right.

The standardized path coefficient of product development and manufacturing capabilities, applied generic technical capability, basic generic technical capacity against personnel loss risk are respectively $0.284,0.383,0.234$, the corresponding $P$ value is significant at the 0.05 level, indicating the product development and manufacturing capabilities, applied generic technical capability, basic generic technology capability can exert a positive significant impact on contract control. Based on the fact that the standardized path coefficient of contract control against personnel loss risk, theft risk of intellectual property, intellectual property rights leakage risk and intellectual property investment risk is respectively $-0.153,-0.203,-0.428,-0.220$, the corresponding $\mathrm{P}$ value is significant over the 0.005 level, indicating that contract control can exert significant negative impact on personnel risk risk, theft risk of intellectual property, Knowledge leakage risk and intellectual property investment risk.

\subsection{Bootstrap Mesomeric Effect Test}

It is shown in the Table 12 that all the corresponding $\mathrm{P}$ value is significant over the 0.005 level. Mediating effect can meet expectations.

\section{Conclusion}

Referring to the matching of technological capability structure, this paper studies its influence on intellectual property risk. After comprehensively exploring theory of enterprise technological capability, contract theory and intellectual property risk, it set up the model of the relationship between the technical capability structure and the intellectual property risk and studied mediating role of contract control. Through the questionnaire survey, the model is verified. The following conclusions can be reached after theoretical analysis and empirical analysis: 
Table 12. Bootstrap standardized effect table.

\begin{tabular}{|c|c|c|c|c|c|c|}
\hline Effect & independent variable & $\begin{array}{l}\text { Contract control } \\
\text { (significant) }\end{array}$ & $\begin{array}{l}\text { Intellectual property } \\
\text { investment risk } \\
\text { (significant) }\end{array}$ & $\begin{array}{l}\text { Knowledge } \\
\text { leakage risk } \\
\text { (significant) }\end{array}$ & $\begin{array}{l}\text { Theft risk of intellectual } \\
\text { property rights } \\
\text { (significant) }\end{array}$ & $\begin{array}{c}\text { Personnel } \\
\text { turnover risk } \\
\text { (significant) }\end{array}$ \\
\hline \multirow{4}{*}{$\begin{array}{l}\text { Standardized } \\
\text { direct effect }\end{array}$} & $\begin{array}{c}\text { Basic generic } \\
\text { technology capability }\end{array}$ & $0.234(0.000)$ & $-0.320(0.000)$ & $-0.181(0.002)$ & $-0.259(0.000)$ & $-0.215(0.000)$ \\
\hline & Applied generic skills & $0.383(0.000)$ & $-0.231(0.000)$ & $-0.141(0.017)$ & $-0.253(0.000)$ & $-0.311(0.001)$ \\
\hline & $\begin{array}{l}\text { Product development and } \\
\text { manufacturing capabilities }\end{array}$ & $0.284(0.001)$ & $-0.126(0.042)$ & $-0.201(0.001)$ & $-0.280(0.000)$ & $-0.231(0.000)$ \\
\hline & Contract control & & $-0.220(0.004)$ & $-0.428(0.001)$ & $-0.203(0.010)$ & $-0.153(0.046)$ \\
\hline \multirow{4}{*}{$\begin{array}{l}\text { Standardized } \\
\text { indirect effect }\end{array}$} & $\begin{array}{c}\text { Basic generic } \\
\text { technology capability }\end{array}$ & & $-0.052(0.002)$ & $-0.100(0.000)$ & $-0.048(0.005)$ & $-0.036(0.029)$ \\
\hline & Applied generic skills & & $-0.084(0.002)$ & $-0.164(0.000)$ & $-0.078(0.007)$ & $-0.058(0.036)$ \\
\hline & $\begin{array}{l}\text { Product development and } \\
\text { manufacturing capabilities }\end{array}$ & & $-0.063(0.003)$ & $-0.122(0.000)$ & $-0.058(0.007)$ & $-0.043(0.037)$ \\
\hline & Contract control & & & & & \\
\hline \multirow{4}{*}{$\begin{array}{c}\text { Total effect of } \\
\text { standardization }\end{array}$} & $\begin{array}{c}\text { Basic generic } \\
\text { technology capability }\end{array}$ & $0.234(0.000)$ & $-0.371(0.000)$ & $-0.281(0.000)$ & $-0.306(0.000)$ & $-0.251(0.000)$ \\
\hline & Applied generic skills & $0.383(0.000)$ & $-0.316(0.000)$ & $-0.305(0.001)$ & $-0.331(0.000)$ & $-0.369(0.001)$ \\
\hline & $\begin{array}{l}\text { Product development and } \\
\text { manufacturing capabilities }\end{array}$ & $0.284(0.001)$ & $-0.189(0.002)$ & $-0.322(0.000)$ & $-0.337(0.000)$ & $-0.274(0.000)$ \\
\hline & Contract control & & $-0.220(0.004)$ & $-0.428(0.001)$ & $-0.203(0.010)$ & $-0.153(0.046)$ \\
\hline
\end{tabular}

\subsection{Intellectual Property Risk Classification}

This paper studied intellectual property risk caused by the opportunism. Combining theory and practical experience, the intellectual property risk is divided into the loss of intellectual property and intellectual property investment risk, moreover, the intellectual property loss risk is further subdivided into three dimensions of personnel turnover risk, theft risk of intellectual property related to cooperative innovation and risk of intellectual property leakage unrelated to cooperative innovation. According to the data generated from the questionnaire, exploratory factor analysis and confirmatory factor analysis were performed to verify the classification of the data.

\subsection{Different Dimensions of Enterprise Technological Capability Structure Can Exert Different Influence on the Intellectual Property Risk}

Based on theoretical analysis, this paper aims to establish influencing model for each dimension of the technological capability structure on the various dimensions of intellectual property risk in cooperative innovation. Through structural equation model analysis of obtained questionnaire data, the influencing model of enterprise technological capability structure matching against intellectual property risk can be generated. Overall, enterprise technological capability structure matching can exert negatively significant effect on intellectual property 
investment risk, but there are differences between the different dimensions of the enterprise's technological capability structure and different dimensions of the loss of intellectual property rights. For example, the influence of product development and manufacturing capability matching on theft risk of intellectual property rights and risk of intellectual property leakage unrelated to cooperative innovation is more prominent than another two dimensions. However, the influence of applied generic technology matching is more obvious than personnel turnover risk and basic generic technology matching is more obvious than intellectual property investment risk.

\subsection{The Mediating Role of Contractual Control in the Impact of Relational Embeddedness on Intellectual Property Risk}

This paper adopts the contract control as an intervening variable for empirical research, and it can be found based on structural equation analysis of questionnaire data that, overall, the three dimensional matching of enterprise technological capability can exert positively significant impact on contract control. The contract control can exert a negatively significant effect on each dimension of intellectual property risk. After adding the intervening variables, the path coefficient of various dimensions for enterprise technological capability structure against intellectual property risk is significantly decreased. In addition, the technical capability structure of the enterprise is significantly correlated to the contract control and the contract control is significantly correlated to intellectual property risk. Therefore, it is proved that the control method is suitable as an intervening variable.

This paper still has the following limitations:

1) Subject investigated is monistic. Due to the difficulties in technology and capability to some degree, this study only collects data from the perspective of enterprise, performs empirical study and then the conclusions are applied to enterprise. But production-learning-research cooperation should be the innovation process in partnership with enterprise, university and scientific research institution. The study of university and scientific research institution is absent in this paper. In addition, subjective evaluation method is used by enterprises when collecting data. Though the selected respondents are middle-level managers or above, incomprehension and judgment error cannot be avoided, affecting the final data.

2) Research on intellectual property risk is still immature. At present, most of the research on intellectual property rights is in the angle of law. Research on intellectual property risk in management perspective is not systematic and in-depth. Taking classification of intellectual property risks as an example, there is no uniform standard and the manifestation of derivative intellectual property risk will be more diverse with the continuous development of productionlearning-research cooperation. At the same time, the research on the intellectual property risk and the performance of production-learning-research cooperation should also be the focus in the next phase of research. 


\section{Fund}

1) The major project of the National Natural Science Fund: "Research on the theory and policy of production-learning-research cooperation" (71233003).

2) Project of Planning Fund of the Ministry of Education, Humanities and Social Sciences: "Research on Governance Model of Innovation Alliance of Production-learning-research Based on Technology Integration and Cooperation" (15YJA630008).

3) Key Projects of Ministry of Education, Philosophy and Social Sciences Research: "Research on Theory, Mechanism and Policy of Collaborative innovation" (12JZD042).

\section{References}

[1] Zhou, M. (2006) The Structure and Evolution of the Technological Capabilities of Enterprises. South China University of Technology, Guangzhou.

[2] Li, Q. and Zheng, J. (2013) Heterogeneity, Asymmetry and Mode Selection in Production-Learning-Research Link, University and Research Institute. Review of Production and Management, 4, 26-35.

[3] Liu, J. (2006) A Study on Cooperation Mechanism of Technological Innovation in Regional Universities and Research Institutions and Enterprises. Doctoral Dissertation, Tianjin University, Tianjin.

[4] Wang, H. and Huang, G. (2015) Research on Intellectual Property Risk of Industry University Cooperative Innovation. Science and Technology Management Research, No. 3, 130-135.

[5] Zhang, K. and Huang, R. (2007) Intellectual Property Risk Analysis of Partner Opportunism Behavior. Science Research, 25, 740-744.

[6] Huang, Y. (2011) An Empirical Study on the Impact of Relationship Embeddedness on the Intellectual Property Risk in Industry University Research Cooperation Innovation. Doctoral Dissertation, Fuzhou University, Fuzhou.

[7] Su, S. and Huang, R. (2009) Research on Intellectual Property Risk and Its Countermeasures in Tacit Knowledge Transfer in Cooperative Innovation. Science and Technology Progress and Countermeasure, 26, 118-121.

[8] Williamson, O.E. (1993) Transaction Cost and Theory. Industrial \& Corporate Change, 2, 17-67. https://doi.org/10.1093/icc/2.1.107

[9] Williamson, O.E., Oliver, E., Yi and Wang, W. (2002) The Capitalist Economic System. The Commercial Press, Shanghai.

[10] Das, T.K. and Teng, B.S. (1996) Risk Types Inter-Firm Structures. Journal of Management, No. 6, 11-15.

[11] Liu, M. and Li, G. (2012) The Evolutionary Game Analysis of the Cooperation of Industry, University and Research Institute. Industrial Technology Economics, No. 10, 137-143.

[12] Delerue, H. (2004) Relational Risks in Biotechnology Alliances. The Effect Contextual European Management Journal, No. 5, 546-556.

[13] Xing, Z., Huang, R., et al. (2008) Knowledge Loss Risk and Knowledge Protection in Alliance Cooperation: The Moderating Effect of Trust. Nankai Management Review, 11, 27-30.

[14] Jap, S.D. and Ganesan, S. (2013) Control Mechanisms and the Relationship Life Cycle, Implications for Safe Guarding Specific Investments and Developing Com- 
mitment. Journal of Marketing Research, 37, 227-245.

https://doi.org/10.1509/jmkr.37.2.227.18735

[15] Gulati, R. and Singh, H. (1998) The Architecture of Cooperation: Managing Coordination Costs and Appropriation Concerns in Strategic Alliances. Administrative Science Quarterly, 43, 781-814.

\section{Scientific Research Publishing}

Submit or recommend next manuscript to SCIRP and we will provide best service for you:

Accepting pre-submission inquiries through Email, Facebook, LinkedIn, Twitter, etc. A wide selection of journals (inclusive of 9 subjects, more than 200 journals)

Providing 24-hour high-quality service

User-friendly online submission system

Fair and swift peer-review system

Efficient typesetting and proofreading procedure

Display of the result of downloads and visits, as well as the number of cited articles Maximum dissemination of your research work

Submit your manuscript at: http://papersubmission.scirp.org/

Or contact ojbm@scirp.org 